\title{
A Review of the Assessment Tools for the Efficiency of Nanolime Calcareous Stone Consolidant Products for Historic Structures
}

\author{
Styliani Papatzani ${ }^{1,2, *(1)}$ and Emmanouil Dimitrakakis ${ }^{3}$ \\ 1 Department of Mathematics and Engineering Sciences, Hellenic Army Academy, 16672 Attika, Vari, Greece \\ 2 Hellenic Ministry of Culture and Sports, Directorate for the Restoration of Byzantine and Post-byzantine \\ Monuments, 11742 Athens, Greece \\ 3 Marpol Fleet Ship Management S.A., 18545 Piraeus, Greece; emmdimitrakakis@gmail.com \\ * Correspondence: spapatzani@gmail.com
}

Received: 27 October 2019; Accepted: 15 November 2019; Published: 16 November 2019

check for updates

\begin{abstract}
In the present review paper, the term "effectiveness" of nanolime consolidants was redefined by presenting a suite of efficiency parameters/material properties that must be assessed in order to compare available treatments for weathered calcareous stones for historic buildings. Assessment tools in the form of characterization methods for synthetized nanolime dispersions, artificial weathering techniques, and treated calcareous stones were correlated and discussed, giving rise to non-destructive testing methods. The effect of the application method and dispersion medium was also presented. It was concluded that the presented suite of efficiency parameters and characterization techniques can be applied to further studies for the development of mass consolidation procedures in order to reach penetration depths well beyond the $5.5 \mathrm{~cm}$ threshold achieved up to date.
\end{abstract}

Keywords: consolidants; nanolime; calcareous stones; heritage preservation; characterization methods

\section{Introduction}

Major causes of physical and chemical deterioration of natural stones in historic structures include crystallization of soluble salts causing salt weathering (Figure 1), frost, pollutants, vegetation growth (Figure 2), seismic effects and combinations of all the above (Figure 3). The common ground for all these causes of deterioration is the moisture that penetrates into the stones. The outcome of the decay is loss of cohesion (sanding, powdering, and/or chalking), delamination/exfoliation or cracking of the material [1], and detachment of the outermost layers, leading to a decrease in strength [2]. 


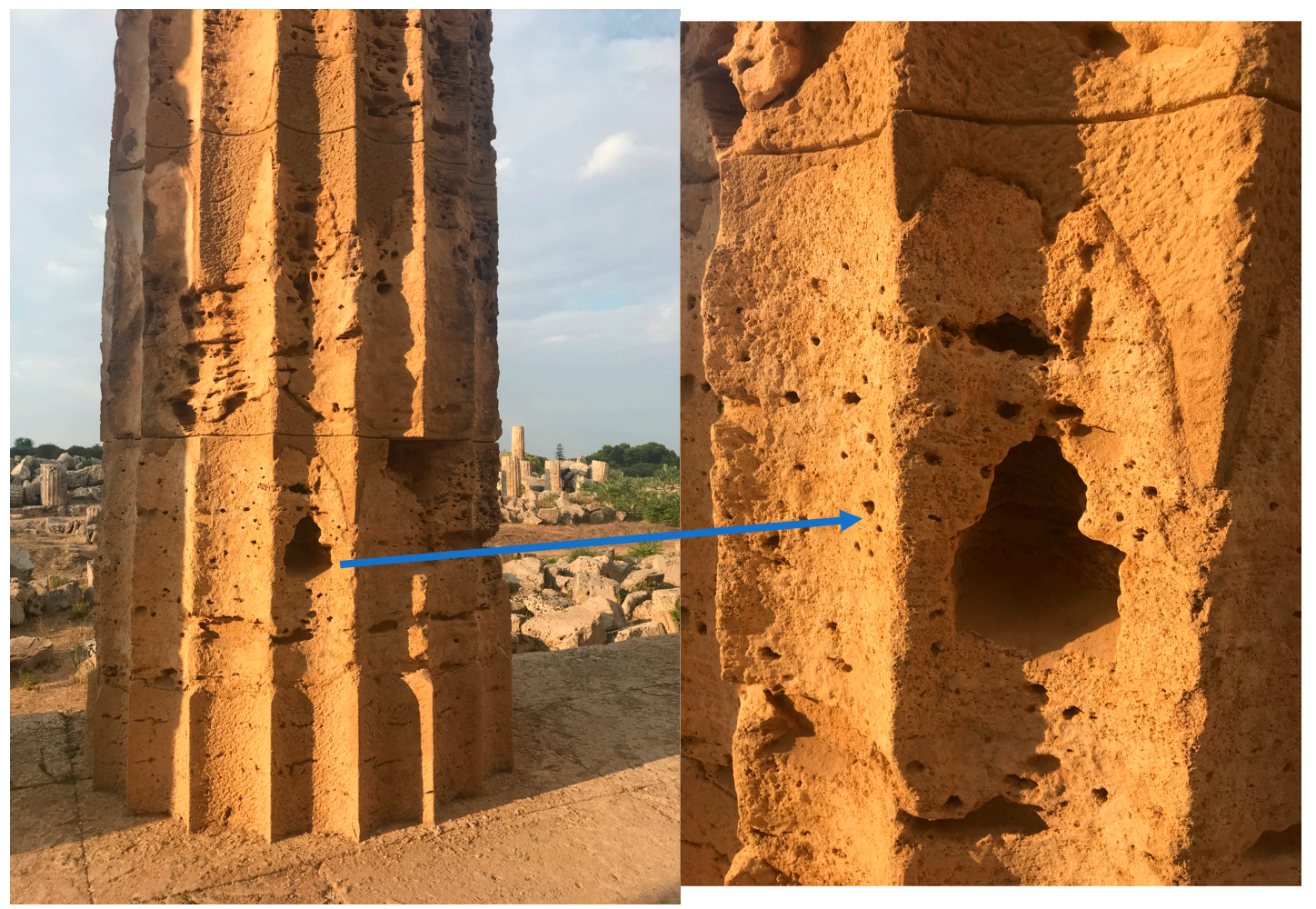

Figure 1. Salt weathering, The Temple of Hera (Temple E), Selinunte, Sicily, Italy, September 2019.

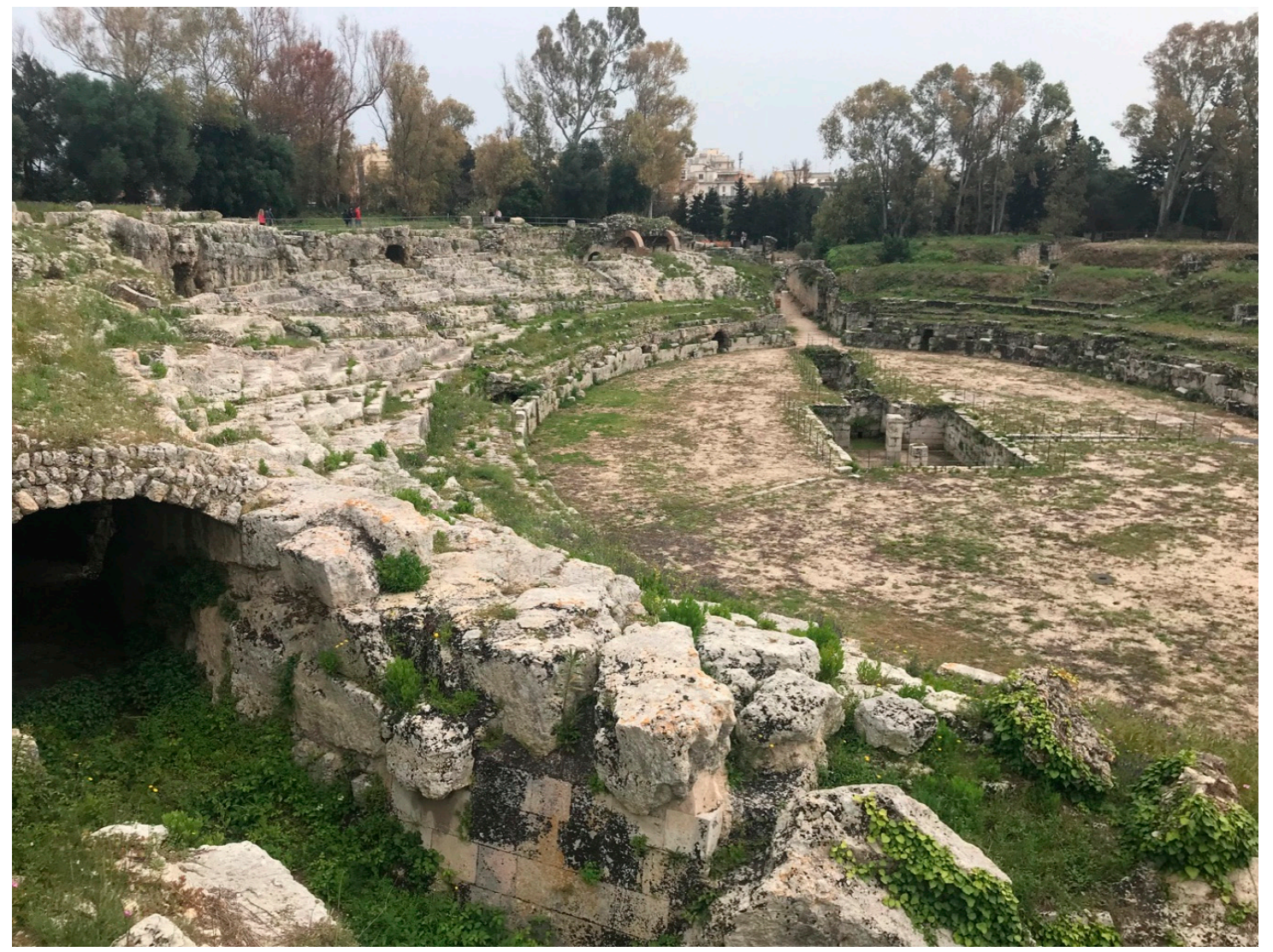

Figure 2. Vegetation growth. The Greek Theatre of Syracuse (UNESCO World Heritage Site), Sicily, Italy, April 2019. 


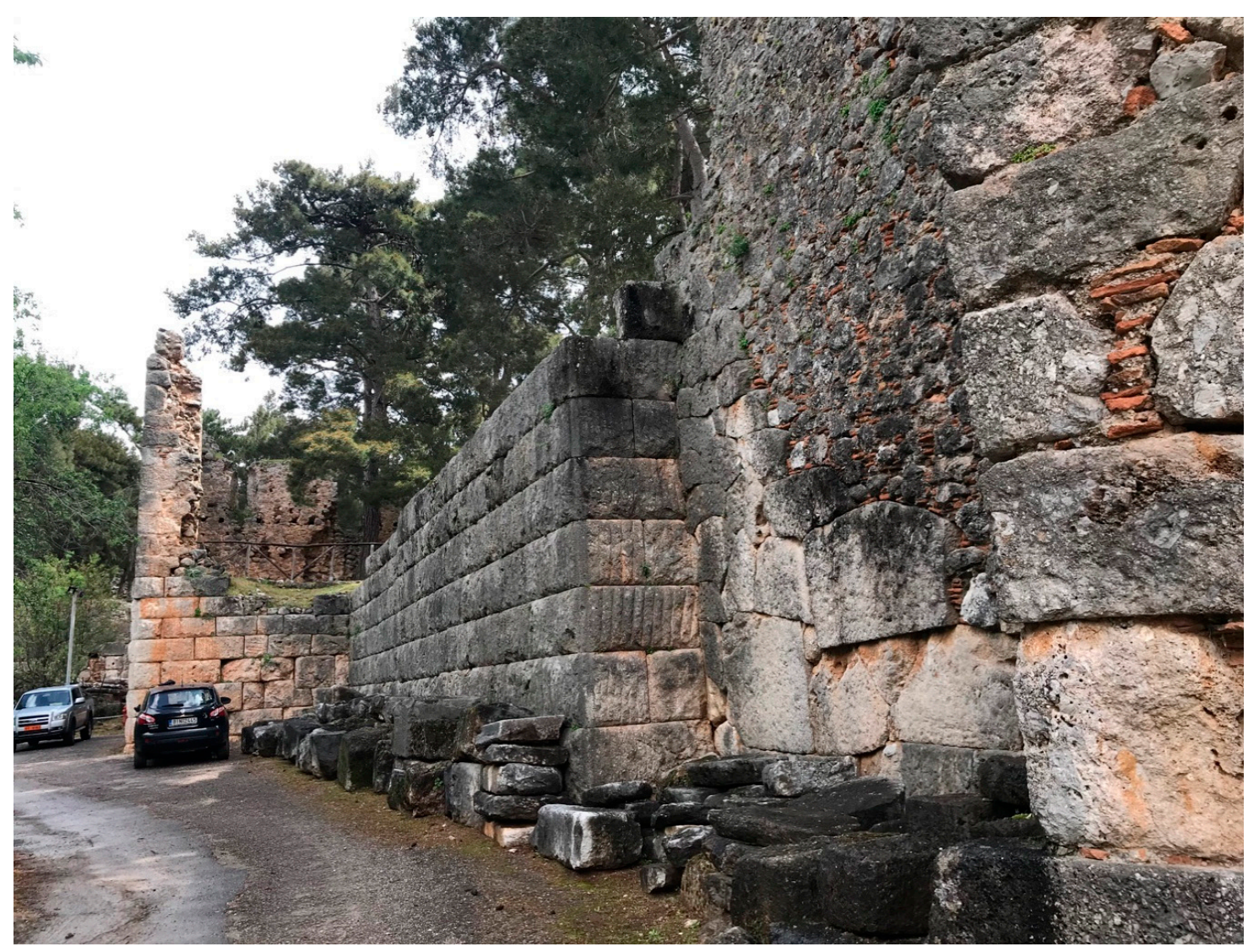

Figure 3. Combined decay: seismic effects, salt weathering, vegetation growth, and different construction phases over centuries. Apparent exfoliation and detachment of the outermost layers of the stone. The Castle of Amfissa, Greece, March 2019.

In fact, most frequently, decay is initiated by water penetration and aggravates with time, as the cycles of wetting and drying continue (Figure 4). Stones in coastal areas are even more severely affected by salt weathering (Figure 5). As all masonry structures degrade by weathering, consolidation is one of the most widely accepted treatments offered. Consolidation, essentially, is a detailed process by which consolidants are applied on weathered stones (plaster or mortar) in order to enhance the cohesion, restore mechanical strength, and impede further physical and chemical degradation. Consolidants should mimic the natural stone in terms of strength, cohesion, porosity, permeability, hardness, chemical proximity, color, thermal dilation, and others. However, the strength provided by the consolidant should not surpass the strength of the underlying sound stone [1].

With the advent of nanotechnology, suspensions of nanoparticles have attracted the attention of a range of materials' scientists for a significant variety of applications [3]. In the case of the development of suspensions of nanoparticles suitable for consolidation purposes, they can function as:

1. Nanofillers, reducing the nanoporosity;

2. Nano-reinforcements, increasing mechanical strength;

3. Catalysts, due to the fact of their higher surface area/volume ratio. 


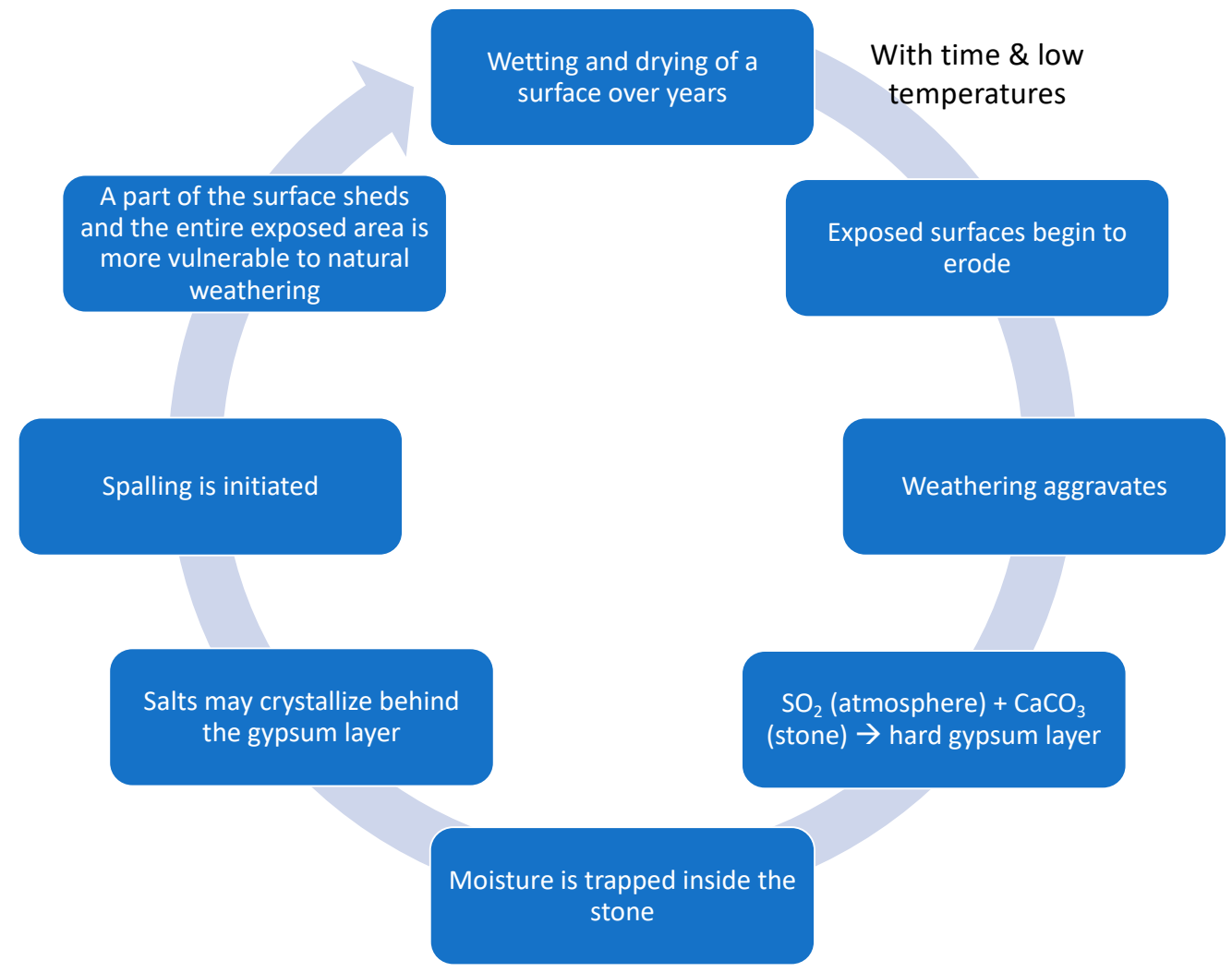

Figure 4. The cycle of stone decay.
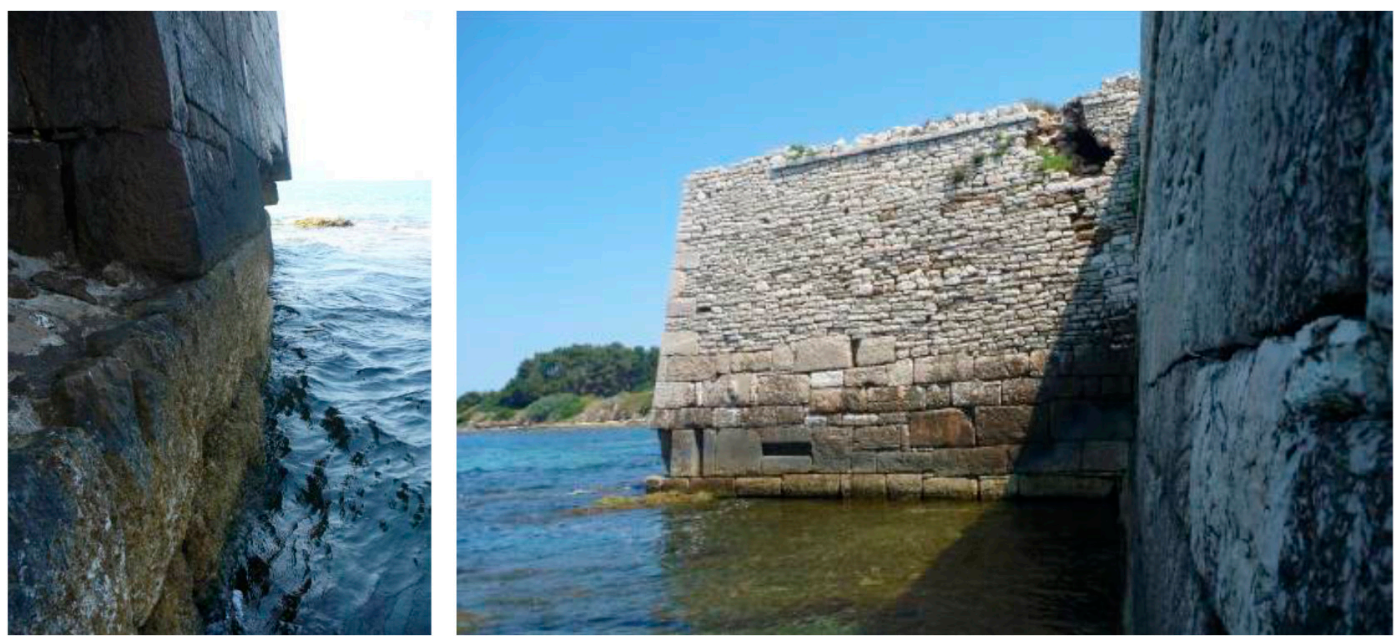

Figure 5. Combined decay: seismic effects, salt weathering in coastal areas, vegetation growth, and different construction phases over centuries. Extreme corrosion of all stones undergoing wetting and drying. The Castle of Preveza, Greece, June 2017.

Consolidant products can be based on inorganic nanoparticles of $\mathrm{Ca}(\mathrm{OH})_{2}, \mathrm{Mg}(\mathrm{OH})_{2}, \mathrm{Ba}(\mathrm{OH})_{2}$, $\mathrm{Sr}(\mathrm{OH})_{2}, \mathrm{SiO}_{2}$, calcium alkoxides [4], tetraethoxysilane (TEOS)-nano-calcium oxalate [5], hydroxyapatite or silicon-based hybrid polymer nanocomposites [6]. Recently, alkoxysilanes were proven to function in a deteriorating way for calcareous stones forming isolated aggregates within the pores of calcareous stones, whereas, for siliceous stones, gelling of the sols created a continuous film, closing the pores (Figure 6) [7]. A number of experimental results were provided including attenuated total reflection infrared spectroscopy (ATR-FTIR), ${ }^{29}$ Si magic-angle spinning (MAS) spectroscopy, $\mathrm{pH}$ measurements, scanning electron microscopy (SEM). 


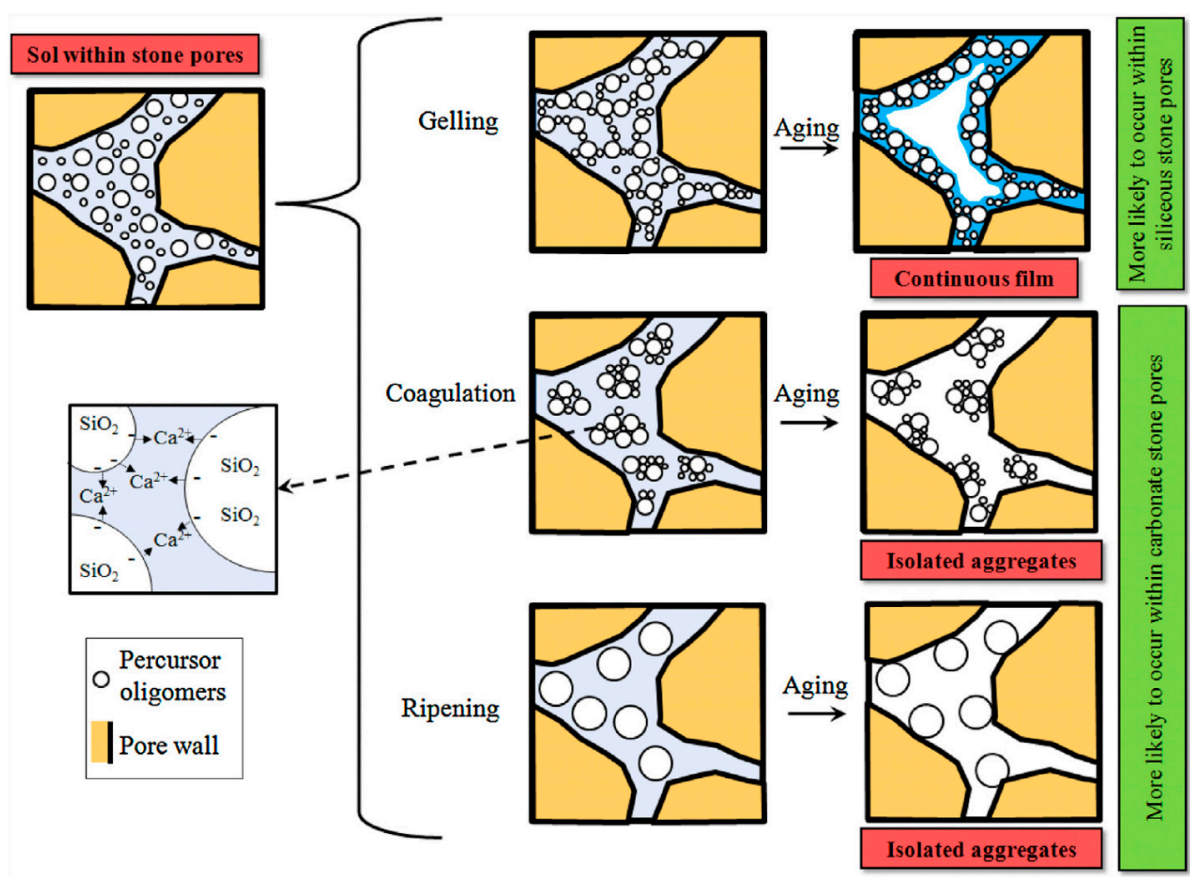

Figure 6. The sol-gel process within the pores of stones that produce silicate gel and xerogel/precipitates. Rounded particles are composed of small siloxanes (Si-O-Si) [7].

This paper focused on the nanolime treatments of calcareous stones, i.e., limestones, marbles, dolostones, and calcarenites. Nanolime remains one of the most widely used consolidants due to the chemical and structural affinity and, subsequently, compatibility with calcareous stones. Although traditional lime putty applications can be enhanced with the use of various nanoparticles, for example, nano-montmorillonites [8], in comparison to traditional pure limewater, nanolimes offer higher lime concentrations, exhibit higher reactivity and kinetic stability, and provide deeper penetration into the substrate. D'Armada and Hirst [9] gave the following example: CaLoSiL®E-50 contains $50 \mathrm{~g}$ of lime per liter which is approximately 30 times greater than the quantity of lime in limewater.

Furthermore, the limited solubility of $\mathrm{Ca}(\mathrm{OH})_{2}$ in water (for the traditional limewater method) and the need to limit the presence of water in order to reduce mobilization of salts and freeze-thaw weathering, render nanolime a more promising consolidant [10]. Nanolime, essentially, consists of nanoparticles of $\mathrm{Ca}(\mathrm{OH})_{2}$ suspended in alcohol. According to the literature, the range in the diameter of the nanoparticles lies within 50-300 $\mathrm{nm}$ (Table 1), whereas commercial nanolimes can have a spherical or hexagonal shape, and their size can reach up to $600 \mathrm{~nm}$ diameter [2]. It is interesting to note the difference in size to conventional lime hydrates which is in the order of $103 \mathrm{~nm}$, similar to the pore radius (Table 1).

Table 1. Sizes of different particles [9].

\begin{tabular}{cc}
\hline Particle & Ionic Radius $\mathbf{( n m}=\mathbf{1 0}^{\mathbf{- 9}} \mathbf{~}$ ) \\
\hline Calcium ion & 0.1 \\
Hydroxyl ion & 0.14 \\
Nanolime & $50-300$ \\
Conventional lime hydrate & $\sim 10^{3}-10^{5}$ \\
Pore space & $\sim 10^{3}-10^{4}$ \\
\hline
\end{tabular}

The fineness of the particles is ideal for deep impregnation of the decayed stone after application of the solution in layers. The alcohol evaporates and/or disperses, and the carbonation process results 
in the formation of calcium carbonate which then fills cracks and pores, binds loose grains, and restores the decayed parts of the stone. The chemical formula that corresponds to the process is shown below:

$$
\mathrm{Ca}(\mathrm{OH})_{2}+\left(\mathrm{H}_{2} \mathrm{O}+\mathrm{CO}_{2}\right)=\mathrm{CaCO}_{3}+2 \mathrm{H}_{2} \mathrm{O}
$$

It is acknowledged that, apart from the general formula (1), carbonation involves a number of steps that can be traced in the literature [11]. In general, nanolime compared to traditional lime water, in addition to the properties mentioned above, can offer higher carbonation rates [12].

Research under the FP7-STONECORE project on the effect of the different suspensions (ethanol, isopropanol, and n-propanol) on the performance of the consolidants suggests that ethanol (CaLoSil@IP-25) is more effective, although it is acknowledged that a number of saturations are needed $[9,13]$. It was also concluded that nanolime consolidants are not suitable for pure sandstones, as the calcium salts produced by the carbonation process are damaging for this material. Tests that directed these conclusions comprised scanning electron imaging measuring the rates and distance of capillary diffusion of the industrial product in three different limestones.

Although significant research results have been published on the effect of nanolime consolidants on the recovery of the superficial cohesion loss in historical structures, research on mass consolidation, which is required for deeper material loss and in-depth decay of calcareous stones, is limited. Furthermore, for all research presented in the field, different assessment tools in the form of characterization techniques were employed, and comparison of findings is complicated. Therefore, a framework of characterization methods analyzing the advantages and disadvantages of all available methods is missing. The focus of the present paper was to review the methods by which consolidant products were characterized and suggest a suite of experiments to assess the effectiveness of the consolidants. The method of treatment/application (i.e., immersion, spray, brushing, pouring, vacuum impregnation, systematic dripping) proposed for calcareous stone preservation and strengthening is also discussed. General synthesis methods of the dispersion of nanoparticles falls beyond the scope of the current method, but synthetized nanolimes compared with commercial nanolimes have been extensively discussed in the present review. The effectiveness was judged in terms of mechanical strength enhancement, surface cohesion, compatibility in terms of color and porosity with the decayed stone, and durability/resistance to deterioration mechanisms. Artificial aging methods employed are also discussed, and the issue of the comparison of laboratory or in situ/field testing and the expected differences in the simulations are also addressed.

\section{Analysis and Discussion}

\subsection{Experimental Techniques Employed for the Characterization of Nanoparticles}

In this section, the methods that were employed for the characterization of the nanoparticles (commercial and tailored) by the research teams discussed in the present review are presented.

\subsubsection{Scanning Electron Microscopy (SEM), Transmission Electron Microscopy} (TEM)/Energy-Dispersive Spectroscopy X-ray (EDX)

Scanning and transmission electron microscopy with the additional feature of $X$-ray energy-dispersive spectroscopy can assist in differentiating the hydrated phases, their chemistry, and their evolution. The thickness of the elements present in the phases can be measured and high-resolution images of over 100,000 times magnification can be captured. However, the densities or volume of pores cannot be measure. Imaging of the surface topography and morphology of the pastes has also been rendered possible with modern SEMs [14,15]. Calcium-to-silica ratios can be calculated with the use of EDX. Moreover, surface morphology can be observed with SEM. Back scattered micrographs of uncoated samples at various magnifications can be obtained using a Jeol $6480 \mathrm{LV}$ scanning electron microscope. The elemental distribution can be studied using SEM/EDX (X-ray 
energy-dispersive spectrometry) at different beam currents. Lastly, field emission electron microscopy (FESEM) allows for capturing images at low voltage and high analysis.

\subsubsection{X-ray Diffraction (XRD)}

X-ray diffraction is used for the characterization of crystalline phases and detection of chemicals in the cement pastes; it has been broadly available for these purposes since the 1950s. By utilizing Bragg's law, the d-spacing or basal spacing (distance between planes of atoms) of the crystalline materials can also be determined. In principle, if the structure is amorphous, the X-rays cannot be diffracted, and a plateau may be observed in the graph of the intensity of the $X$-rays versus $2 \theta$, the angle of diffraction. Still, the plateaus of the amorphous phases detected with XRD are correlate well with other methods, e.g., mass balance calculations [16]. The XRD measures mass fraction, and, with Rietveld analysis (also known as quantitative XRD-QXRD), the quantification of the phases and the determination of their individual contribution in Portland cement (PC) hydration is also possible. The technique is frequently paired with TGA, which also provides mass fraction measurements as in the case of a recent study by which the PC phase distributions were determined by combined QXRD/TGA studies [17].

The state and extent of dispersion of nanoparticles can be examined by XRD and TEM analysis. Apart from mineralogical analysis, XRD is used to probe the structure and measure the interlayer spacing by monitoring the basal reflection of the silicate layers. Changes in basal spacing offer an indication of the intercalation of nano-montmorillonites, for example [3,18-20]. The TEM and, in specific, the study of diffraction patterns can clarify the extent of the dispersion of nanoparticles [21,22].

\subsubsection{UV-Vis}

The stability and quality of the concentrated suspensions can be determined by UV-Vis measurements. With spectroscopic characterization, the predictable radiation attenuation behavior of suspended particles can be exploited. Absorption and scattering behavior are linked with the particle size, refractive index of the particle, and refractive index of the medium in which the particle is dispersed [23]. In essence, UV-Vis measures the intensity of light as it passes through a suspension.

\subsubsection{Dynamic Light Scattering (DLS)}

The size distribution profile of small suspended particles is defined by dynamic light scattering with the use of the intensity or proton auto-correlation function [24]. In essence, DLS measures the light scattered from the laser that passes through a colloidal suspension. Then, the hydrodynamic size of the particles are determined via the modulation of the scattered light intensity as a function of time [25].

\subsubsection{X-ray Fluorescence}

X-ray fluorescence is a non-destructive technique which provides an elemental analysis of materials. Over the past years, its applications have been extended from materials science to archeology and archaeometry, geology, and others. The limitation sensitivities of the technique are up to the $\mu \mathrm{g}-\mathrm{g}^{-1}$ (ppm) range.

\subsection{Results of the Characterization of Nanolime Dispersions}

In this section, all characterization techniques for the assessment of commercial or customized/tailored nanolime dispersions are presented and the results discussed.

In a research paper published in 2008, nanolime particles were produced using a chemical precipitation process in supersaturated aqueous solutions, to which isopropanol was added next in order to obtain a final concentration of $15 \mathrm{mg} / \mathrm{mL}$ [26]. Alcohol was used for improved de-agglomeration and stability of the suspension. In view of the scope of the paper to monitor the carbonation process. Firstly, the nanoparticles were characterized. X-ray diffraction analysis, scanning electron microscopy, 
and transmission electron microscopy imaging were performed and TEM dark field images were also taken.

In a subsequent study by López-Arce et al. [27], nanoparticles of slacked lime, under the commercial name Nanorestore $囚$, were applied to calcareous substrates of dolostones, and the effectiveness was tested via non-destructive techniques (NDTs). The nanoparticle solution was characterized via XRD, TEM, and an environmental scanning electron microscope (ESEM). Aggregates of hexagonal crystals with particle size in the range of $59 \pm 23 \mathrm{~nm}$ were detected. The TEM crystallographic analyses verified the polycrystalline character of the nanolime dispersion witnessed by the rings formed. These findings were in agreement with the XRD findings.

Daniele and Taglieri [28] developed different suspension concentrations (of water over isopropanol) and explored the effect of the residual water of the suspension on the treated stones. $\mathrm{NaCl}$, which was produced by the precipitation reaction between $\mathrm{NaOH}$ and $\mathrm{CaCl}_{2}$, was removed by deionized water washings in order to avoid potential efflorescence. Nanoparticles were characterized via XRD.

The particle size of commercial nanolime CaLoSiL®E25 was assessed via TEM and was found to be in the range of 50-300 $\mathrm{nm}$. Clear hexagonal crystals were detected. The particle size of commercial nanolime CaLoSiL@IP25 was assumed to be similar [29]. In fact, in a later study, Borsoi et al. [2], who carried out SEM/EDX analyses, confirmed the similar size $(50-600 \mathrm{~nm})$ and shape of the two commercial nanolimes. The XRD analyses carried out by Borsoi et al. [2] confirmed the presence of pure calcium hydroxide. Lastly, it should be noted that the letter " $E$ " denotes dispersion in ethanol. The letters "IP" denote dispersion in isopropanol.

In 2013, López-Arce et al. [30] studied the short (20 days) and long-term (18 months) consolidation effects of nanolime in terms of crystallinity and mineralogy via XRD and particle agglomeration via ESEM. It was found that at $75 \%$ relative humidity $(\mathrm{RH})$, after 20 days, needle-like vaterite microcrystals $(1.98-6 \mu \mathrm{m})$ had developed. At 18 months, micron-sized vaterite and aragonite particles $(3-5 \mu \mathrm{m}$ and $8-10 \mu \mathrm{m})$ were associated to calcite $(2.5-3.5 \mu \mathrm{m})$. The presence of these crystals was confirmed with XRD. For the nanolime exposed to lower RH (33\%), clusters of portlandite of poor crystallinity were observed.

Borsoi et al. [2], who suggested that the stability of the nanolime dispersion should be linked with the porosity and pore size of the substrate, examined the kinetic stability of the synthetized dispersions with UV-Vis spectroscopy. The nanolime dispersions were prepared using sonication for $1 \mathrm{~h}$, and UV-Vis measurements commenced directly after the preparation as a function of time for up to $96 \mathrm{~h}$ as in the case of DLS measurements. The relative kinetic stability parameter (KS\%) of dispersions was calculated using analytical calculations. They also assessed the morphology and size of the nanoparticles using dynamic light scattering and SEM-EDX. The XRD was used for the determination of the mineralogical composition.

Weththimuni et al. [31] characterized their synthetized nanolime dispersions via DLS, SEM imaging, and XRD analysis. The DLS showed that $99 \%$ of the particles dispersed in isopropanol had a size that ranged between 40 and $120 \mathrm{~nm}$. The SEM confirmed these dimensions although re-agglomeration was also observed.

Taglieri et al. [32] synthetized three dispersions at room temperature and ambient pressure: (i) a water/isopropanol dispersion with a solid concentration of $5 \mathrm{~g} / \mathrm{L}$; (ii) a water/isopropanol dispersion with a solid concentration of $10 \mathrm{~g} / \mathrm{L}$; and (iii) a water/1-butanol dispersion of a solid concentration of $5 \mathrm{~g} / \mathrm{L}$. The dispersions of nanoparticles were characterized via TEM, XRD, and UV/Vis [32]. The TEM confirmed the size of the hexagonal nanoparticles to be below $20 \mathrm{~nm}$ with a tendency to agglomerate. Pure portlandite was identified after synthesis via XRD. The XRD also showed that dispersions (i) and (ii) offered a complete carbonation process, dispersion (iii) caused a partial conversion into calcite. The metastable form of calcium carbonate hydroxide hydrate $(\mathrm{CCH})$ was also detected. Kinetic stability studies showed that dispersions (i) and (iii) were stable in the first two hours, whereas (ii) settled in the first $5 \mathrm{~min}$. 
Non-commercial nanolimes were also synthetized by Daniele et al. [33] according to patented procedures: (a) an alcoholic dispersion in pure ethanol; (b) a water/ethanol mixture W/A $=50 \%$; (c) an aqueous dispersion in pure water. The carbonation reaction was monitored at $75 \% \mathrm{RH}$ via $\mathrm{XRD}$ and the kinetic stability of the dispersions via UV/Vis. All samples offered a complete conversion of portlandite into pure calcite. Kinetic stability studies showed that all dispersions were stable during the first $5 \mathrm{~min}$. Dispersion (a) was stable through the test, whereas the other two samples showed a slow settling rage, giving enough time for the application to be completed.

\subsection{Artificial Aging Techniques}

In order to carry out experimental work, in most cases, sound stones are extracted from the source quarry of the area from which material for the historical construction was used. Then, artificial aging techniques must be applied in order to obtain weathered specimens. In this section, the techniques applied by scientists, whose work on the consolidation of calcareous stones is discussed in the next sections, are presented.

Ruffolo et al. [34] applied artificial degrading by salt crystallization to limestones extracted from a historical Sicilian quarry. Cubic specimens $(4 \mathrm{~cm} \times 4 \mathrm{~cm})$ underwent the salt crystallization tests described in the BS-EN 12370:1999 regulation [35,36].

Lubelli et al. [1] recently presented a technique for the artificial weathering of stones. Their research was aimed at producing a substrate using artificial weathering procedures which could simulate more reliably natural weathering. The method comprises the following main steps:

1. Grinding and sieving of stones to selected particle sizes similar to that of sound stones;

2. Mixing of grains with air lime powder;

3. Application of the produced "mortar" at the top layer of the stone after pre-wetting of the surface;

4. Curing for two weeks at $20{ }^{\circ} \mathrm{C}, 65 \% \mathrm{RH}$, and $0.5 \% \mathrm{CO}_{2}$.

The method was validated for both the fresh stone and the re-aggregated layer via (i) MIP for the pore structure; (ii) polarized and fluorescent microscopy for the petrographical properties; (iii) water absorption tests BS-EN 13755:2008 [37]; and (iv) drilling resistance measurement tests (SINT technology, described in Section 2.2.) for the hardness profile which constitutes an indirect strength assessment.

The developed re-aggregated layer conformed with the three basic requirements, with respect to the sound fresh stone, of (i) more open structure; (ii) lower strength; and (iii) adequate adhesion to the non-weathered front. The tests employed satisfactorily assessed the abovementioned characteristics.

Bonazza et al. [38] applied thermal stress to specimens of Carrara marble by exposing them at $600{ }^{\circ} \mathrm{C}$ for one hour which, according to other published research, led to complete structural disintegration. The thermal stress induced led to granular disaggregation and material exfoliation.

Weththimuni et al. [31] applied two different methods: (i) 15 freezing-thawing cycles by freezing at $-18{ }^{\circ} \mathrm{C}$ for $18 \mathrm{~h}$ and thawing at $20^{\circ} \mathrm{C}$ for $6 \mathrm{~h}$ the specimens in each cycle; and (ii) 15 wetting-drying cycles according to ASTM D5313 [39] by immersing specimens in distilled water for $6 \mathrm{~h}$ at room temperature and drying them for $24 \mathrm{~h}$ in an oven at $105 \pm 3{ }^{\circ} \mathrm{C}$ in each cycle [31].

\subsection{Assessment Tools for Nanolime-Treated Calcareous Stones}

In this section, a thorough presentation of all published research in the last decade on the consolidation of calcareous stones with nanolime dispersions is presented and discussed. Focus is given to the assessment tools/experimental techniques employed for each material property to be defined. All research with main findings is presented concisely in Table 2.

The nanolime solution prepared by Daniele et al. [26] was applied on the stones with the help of a brush and baking soda solution. The SEM measurements were taken to ascertain the penetration depth (30 $\mu \mathrm{m}$ for Estoril and $1 \mathrm{~mm}$ for pietra serena) [26]. The effectiveness of the application of the nanoparticles was measured with the use of a porosimeter in order to calculate the total pore volume, the average pore radius, and the total porosity of the two lithotypes. With the Scotch Tape test materials 
removed from the surface of the stone before and after treatment were measured. Capillarity and water absorption measurements were also taken according to Italian norms UNI 10859:2000. In 2010, the normative was superseded by UNI EN 15801:2010 [40]. This testing suite did not cover the color alterations, the possible efflorescence phenomena, and the influence of relative humidity which is decisive for the consolidation process. Moreover, the depth of treatment could only be assumed by the imaging techniques. Lastly, the secondary use of alcohol in the aqueous solution rather than directly dispersing the nanoparticles to an alcohol solution may have affected the penetration ability of the solution [41].

López-Arce et al. [27] treated the top surface of the dolostones with a drop-by-drop application of the commercial nanolimes with the use of a capillary tube. On day one, $1.3 \mathrm{~mL}$ were applied on the surface and five days later another $11.3 \mathrm{~mL}$ were applied. One of the treated samples was considered as a fresh sample to be tested (preventive treatment at $33 \% \mathrm{RH}$ ), whereas the second one of the treated samples (consolidating treatment at $75 \% \mathrm{RH}$ ) was subjected to artificial aging via a protocol of freezing-thawing cycles. Samples were tested before and 20 days after the consolidation via ESEM for the morphology and product distribution, spectrophotometry for chromatic changes, mobile optical surface roughness (OSR) analyses with the development of 3D topography maps to assess the surface roughness, propagation of ultrasound velocity to assess durability issues associated with effective porosity, water absorption was measured by capillarity (using a continuous data-recording ACUASOR) and under vacuum (European standard UNE-EN 1936:1999) to measure hydric behavior and to determine the bulk density and open porosity. This standard has now been superseded by UNE-EN 1936:2007 [42]. Lastly, NMR MRI was performed in order to measure the distribution of water and nanoproducts inside the pores of the dolostones. Overall, the NDTs were found to be reliable and fast. The $75 \% \mathrm{RH}$ sample outperformed the $33 \% \mathrm{RH}$ one by better pore filing and inter-crystalline grain contact enhancement and by non-attacking the dolomite crystals. The NMR technique is preferred for studying the pore structure of the phase of a material without needing to dry the material in question. The NMR studies for consolidation effectiveness can be exploited further by studying the atomic characteristics and bonds of the $\mathrm{CaCO}_{3}$ formed [43].

Continuing the 2008 study, in 2010, Daniele and Taglieri [28], further explored the effectiveness of nanolime treatment by brush, again, but at different suspension concentrations (of water over isopropanol) and explored the effect of the residual water of the suspension on the treated stones. The application to six different lithotypes was evaluated with the Scotch Tape and capillarity tests. The best treated stone (Pietra Serena) was further characterized by mercury intrusion porosimetry to confirm that the diluted suspension filled the micro-pores better. However, no strength tests were carried out to confirm changes in the pore structure of the treated stone.

In 2012, D'Armada and Hirst [9] reported results of the STONECORE project according to which the compressive strength of Maastricht limestone increased from $50 \%$ for two saturations to $93 \%$ for six saturations with CaLoSiL $₫ E 25$ whereas CaLoSiL $® I P 25$ increased from $23 \%$ to $47 \%$ for the same amount of saturations. It should be noted that CaLoSiLßis a commercial product produced by IBZ-Salzchemie GmbH \& Co. and available in different concentrations from 15 to $50 \mathrm{~g} / \mathrm{L}$ of nanoparticles. The authors suggested the use of ethyl silicate solvents in nanolime dispersions for the consolidation of larger voids and delaminated areas in outdoor conditions, explaining the chemistry behind their suggestion, recognizing, however, the possible adverse effects such as salts (particularly gypsum) formation. Lastly, the authors managed, by continuous feeding into the surface of three different unweathered UK limestones (Weldon, Ketton and Clipsham) with CaLoSiL®E25, to attain negligible loss of ethanol by evaporation, and, therefore, the maximum depth of deposition, as measured with the use of phenolphthalein, was between 4 to $5.5 \mathrm{~cm}$. Although the consolidation depth determined by the use of a marking agent was significant, results could be verified with non-destructive techniques such as NMR-MRI or X-ray tomography.

In 2013, Pesce et al. [29] used CaLoSiL®E25 and CaLoSiL®IP25 for two different limestones (sourced from Salisbury Cathedral and Bath Abbey (UK)) at two different conditions, weathered 
and unweathered, and evaluated the consolidation effects using the following tests, before and after treatment; Karsten tube penetration test to compare water absorption from different stones; the Scotch Tape test for measuring the adhesion performed according to ASTM D3359/2009 (now superseded by ASTM D3359/2017 [44]); optical microscopy to monitor the surface characteristics; electron microscopy (SEM coupled with energy-dispersive X-ray EDX) to obtain information on microstructure and chemical composition; mercury intrusion porosimetry to obtain data on porosity-related parameters; and drilling resistance measurements (developed by SINT Technology, Italy, together with the Institute for the Conservation, Promotion of Cultural Heritage at the University of Florence) [29]. For the latter test, drilling resistance curves were drawn against the various drilling depths. Amongst many findings, it was concluded that the solvent carrier (ethanol or isopropanol) did not significantly alter the transport of nanoparticles in the pore structure of the stones. Moreover, the drilling resistance measurements can successfully measure the enhancement in mechanical properties with respect to the depth of the treatment. Lastly, although the MIP, the Karsten tube test, the STT, and SEM for microstructural evaluation confirmed penetration of consolidants into the surface; they were all found to be sensitive to changes attributed to nanolime treatments.

In 2013, López-Arce et al. [30] extended their studies on the short-term (20 days after treatment) by combining results with longer-term (18 months after treatment) consolidation effects of lime nanoparticles on carbonate stones. Commercial nanolime under the name Nanorestore $₫$ was applied with no dilution drop by drop through a capillary tube. In addition to this, NDTs were compared with destructive techniques (MIP and micro-drilling resistance measurement). Specimens were placed in climatic chambers under different relative humidity exposure $(33 \%$ and $75 \% \mathrm{RH})$ and $\mathrm{CO}_{2}$ concentration (500-800 ppm) [30]. In greater detail, for the treated stones, spectrophotometry was used to assess the chromatic changes, ultrasonic velocity was used to evaluate effective porosity, and the distribution of the consolidant which, in turn, affects durability. The NMR was used to estimate the depth of penetration and quantify and locate the distribution of water and of the consolidant inside the pore structure of the stones. The MIP was used to determine the total porosity and the pore side distribution, whereas the drilling resistance measurement was used to determine the penetration depth and to assess if the consolidation process enhanced the resistance of the treated stones. The change in surface roughness was assessed via optical surface roughness (OSR) analyses. Lastly, water absorption by capillarity was carried out to study the hydric behavior through the stone using a continuous data-recording and under vacuum to establish the open porosity, the bulk density, and the quantity of water absorbed by the specimens once they reached saturation. The latter process is described by the Spanish and European standard UNE-EN 1936, now superseded by UNE-EN 1936:2007 [42]. It was concluded that a complete transformation of portlandite $\left(\mathrm{Ca}(\mathrm{OH})_{2}\right)$ to calcite $\left(\mathrm{CaCO}_{3}\right)$ was achieved under $75 \%$ RH providing lower color variations, greater reduction in surface roughness, and a higher increase in the ultrasonic velocity propagation. Carbonation was stopped or slowed down for the samples consolidated under 33\% RH. Lastly, the NDTs corroborated well with the destructive techniques, giving the advantage of testing the same samples over a lengthy period of time therefore allowing to monitor the changes induced with time.

Ruffolo et al. [34] measured the consolidation effectiveness of nanolime on artificially salt-weathered limestones using four techniques: the peeling test, also known as the "Scotch Tape test" (STT), in order to quantify the adhesion of a surface or a near-to-surface layer to the substrate; the point load test (PLT) for the determination of strength; MIP to monitor the variations in porosity and pore size distribution induced by the consolidant; and colorimetric measurements (spectrophotometry) to assess aesthetical compatibility. Specimens were immersed in Nanorestore $($ for three hours; then they were allowed to dry, and tests were carried out a month later. The authors using thermodynamic model equations (Wellman and Wilson), calculated the crystallization pressure (i.e., the pressure that builds up among two connected pores when crystallization takes place) using the pore sizes data for the unaltered, aged, and consolidated limestone specimens. Very interestingly, the authors concluded that for the severely weathered samples (fifteen cycles rather than five cycles), treatment should be 
avoided because the increase in the crystallization pressure within the pores can possibly lead to stone decay. Therefore, the parameter of crystallization pressure, which was first presented by the authors, seems to be a significant value to be taken into consideration. Furthermore, the STT and PLT results were complementary. Although consolidation treatment led to a superficial cohesion, the strength of the stone did not increase.

Borsoi et al. [12] identified one of the challenges in the application of nanolime for mass consolidation (necessary for the restoration of large decayed areas of limestone), being that nanolime accumulates at or beneath the surface of the treated stone, hence, limiting the consolidation depth. For this, they studied the transport mechanism of nanolime on Maastricht limestone. This stone, traditionally used in the Netherlands and Belgium, is highly porous $(50 \%)$, soft (compressive strength of 1.3-5 MPa), and yellowish; in historical structures, it generally suffers from loss of cohesion or loss of material. Different specimens were consolidated with nanolimes dispersed in water or in ethanol (CaLoSiL®E25) and underwent a number of tests: capillary absorption test, drying test (in order to study drying kinetics, the weight loss was measured over time), and phenolphthalein test (for measuring the penetration depth). Lastly, the deposition of nanolime, the drying surface, and the cross-section was observed with the use of a stereomicroscope and SEM-EDX. Core specimens were extracted from sound blocks. Parafilm was used as a sealant for the lateral sides of the cores, and a large mass of the consolidant was added at the top of the core. The researchers concluded that nanolime particles do not simply accumulate at the absorption surface. Nanolime particles penetrate to depths up to $40 \mathrm{~mm}$ and partly back-migrate towards the drying surface, a phenomenon also witnessed by the formation of a white haze on or near the surface. Accumulation of the nanoparticles (beneath the treated surface) occurs during the drying and not during the absorption phase. Moreover, carbonation did not affect the deposition of nanolime within the first $48 \mathrm{~h}$. The MIP tests could have shed more light on the effectiveness of the application, and X-ray tomography could have further supported the findings.

Borsoi et al. [2] subsequently suggested that the stability of the nanolime dispersion should be linked with the porosity and pore size of the substrate and extended their previous work with the study on the effect of the dispersion medium (i.e., ethanol, isopropanol, butanol, and water) on the depth of penetration into the Migné and Maastricht limestones in an effort to optimize the in-depth deposition. The MIP was used for measuring porosity and pore size, and the moisture transport behavior was further assessed by measuring absorption and drying. Similar to their previous study, treated stones were tested via capillary absorption test, drying test, phenolphthalein test, SEM-EDX, and optical microscopy. Ethanol and isopropanol solvents (higher boiling points) gave the most stable dispersions; however, butanol and water solvents (lower boiling points) did not show significant back migration. In fact, for the coarse limestone $\left(\approx 95 \% \mathrm{CaCO}_{3}\right.$, density $\left.=1.25 \mathrm{~g} / \mathrm{cm}^{3}\right)$, nanolime dispersed in butanol penetrated at a $20-25 \mathrm{~mm}$ depth, whereas, for fine limestone $\left(>98 \% \mathrm{CaCO}_{3}\right.$, density $\left.=1.96 \mathrm{~g} / \mathrm{cm}^{3}\right)$, the ethanol solvent performed better than the butanol but phase separation took place. Therefore, although solvents with higher boiling points were suggested for coarse-porous limestones and solvents with lower boiling points for fine-porous stones, optimization of solvents was seen as the next step for better penetration depths.

Borsoi's team [45] extended previous work on mass consolidation by testing combinations of nanolime dispersed with ethanol-based solvents with different percentages of water. They studied the deposition of nanolime particles using the phenolphthalein test and optical and scanning electron microscopy, similar to their previous research. The mixture of ethanol $(95 \%)$ and water $(5 \%)$ provided deeper deposition of nanoparticles within coarse porous substrates (Maastricht limestone), when compared to nanolime particles dispersed in pure ethanol [45].

In a subsequent study, Borsoi et al. [46] applied pure ethanol-based dispersion by nebulization on sound and weathered Maastricht limestone (and the dispersion with binary 95\% ethanol and 5\% water solvent for lime-based mortars, but the study of mortars lies beyond the scope of the present paper). A trigger spray nozzle was used for the nebulization, and the amount of nanolime was calibrated 
for each application which, however, ranged from $0.787 \pm 0.052 \mathrm{~L} / \mathrm{m}^{2}$ for both sound and weathered limestone. Up to 10 applications were allowed, with a time interval determined by previous research on the complete evaporation of the alcoholic solvent to be $48 \mathrm{~h}$. For the applications, the following ambient conditions were kept constant: $50 \% \mathrm{RH}, 20^{\circ} \mathrm{C}$ temperature, and a less than $0.1 \mathrm{~m} / \mathrm{s}$ air speed. For storage, the relative humidity increased to $65 \%$ for a period of three months. The in-depth strength increase was measured via the drilling resistance measurement system (DRMS) which is particularly suitable for soft stones. Capillary absorption tests were also carried out, and the water absorption coefficient (WAC) was determined in agreement with the procedure described in EN 15801:2010 [40]. Chromatic alterations were monitored via photography and digital microscopy. It was concluded that the synthesized nanolime dispersion can reach up to $16 \mathrm{~mm}$ in depth, maximizing its effect in the outer 5-6 mm. Therefore, although in previous research in which the application was carried out by capillary absorption, the $95 \%$ ethanol and $5 \%$ water solvent was ideal for the porous limestones; in the case of a different application-nebulization, the $100 \%$ ethanol solvent offered optimal results. The authors also stressed the need for testing durability-related parameters such as salt crystallization or freeze-thaw resistance.

Given that climate simulation chambers do not fully simulate real conditions in the field, Bonazza et al. [38] studied the effects of consolidating products on field exposed specimens (Figure 7) under the EC project "NANOMATCH". Under this project, a nanolime dispersion was produced, and its application was compared to the application of the commercial product CaLoSilß(calcium hydroxide nanoparticles dispersed in ethanol at $20 \mathrm{~g} / \mathrm{L}$ of calcium). Model samples of Carrara marble were exposed for nine months in monuments in four different European cities with completely diverse climatological conditions: Santa Croce Basilica in Florence (Italy), Cologne Cathedral in Cologne (Germany), Oviedo Cathedral in Oviedo (Spain), and Stavropoleos Monastery in Bucharest (Romania). Temperature, humidity, rain, gases, aerosols from combustion engines, and air quality data with their fluctuations were recorded and published within NANOMATCH. This is the first study in which in situ measurements were not carried out shortly after the application of the consolidant, but all climatic aging effects were allowed to take place in real time and only then were the samples tested for the effectiveness of the consolidation. The aesthetic properties were assessed via spectrophotometry. The morphology and microstructure of the samples were tested with optical microscopy and ESM-EDX. The surface cohesion of the treated samples was assessed using the Scotch Tape test. The amount of water absorbed by the specimens per surface over time was assessed via capillary water absorption measurement (performed according to standard UNI EN 15801:2010 [40]). Lastly, ultrasonic pulse velocity tests (NDT) were carried out in accordance with the standard EN 14579: 2004 [47] to assess the extent of penetration. By capillary absorption tests, it was concluded that artificially weathered but treated specimens absorbed less water after 11 months of exposure than untreated ones before the exposure. The STT tests gave similar results, suggesting that the cohesion increased after the treatment which also explains the decrease in water absorption. However, both materials did not manage to penetrate deep into the substrate. They both remained on the surface as sacrifice material or protective coating rather than functioning as a consolidant. Lastly, heavy rain was found to be the most detrimental of all environmental parameters. The application may be more successful with limestone than marble.

Niedoba et al. [48] presented a protocol on how to modify the distribution of nanolimes inside the pore structure of a Maastricht limestone, while dispersing the nanoparticles in water. Both CaLoSil@E25 and CaLoSil@E50 were amongst the nanoparticle dispersions compared. The volume of the consolidant used for each specimen was equivalent to one-third of the pore volume. Differential X-ray transmission radiography was employed to monitor the distribution of the consolidant inside the pore system, and drilling resistance measurements confirmed the penetration depth of the treatment. Applying water

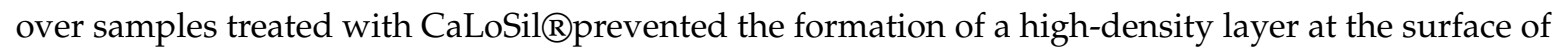
the stone. X-ray radiography also showed that water applied immediately after the nanolime treatment enhanced the homogeneous dispersion of the nanolimes throughout the pore structure of the stone 
under treatment (Figure 8). Up to $3.5 \mathrm{~cm}$ consolidation depths were reached, and the methodology can be adapted to different porosity substrates by varying the proportions of nanolime and water.

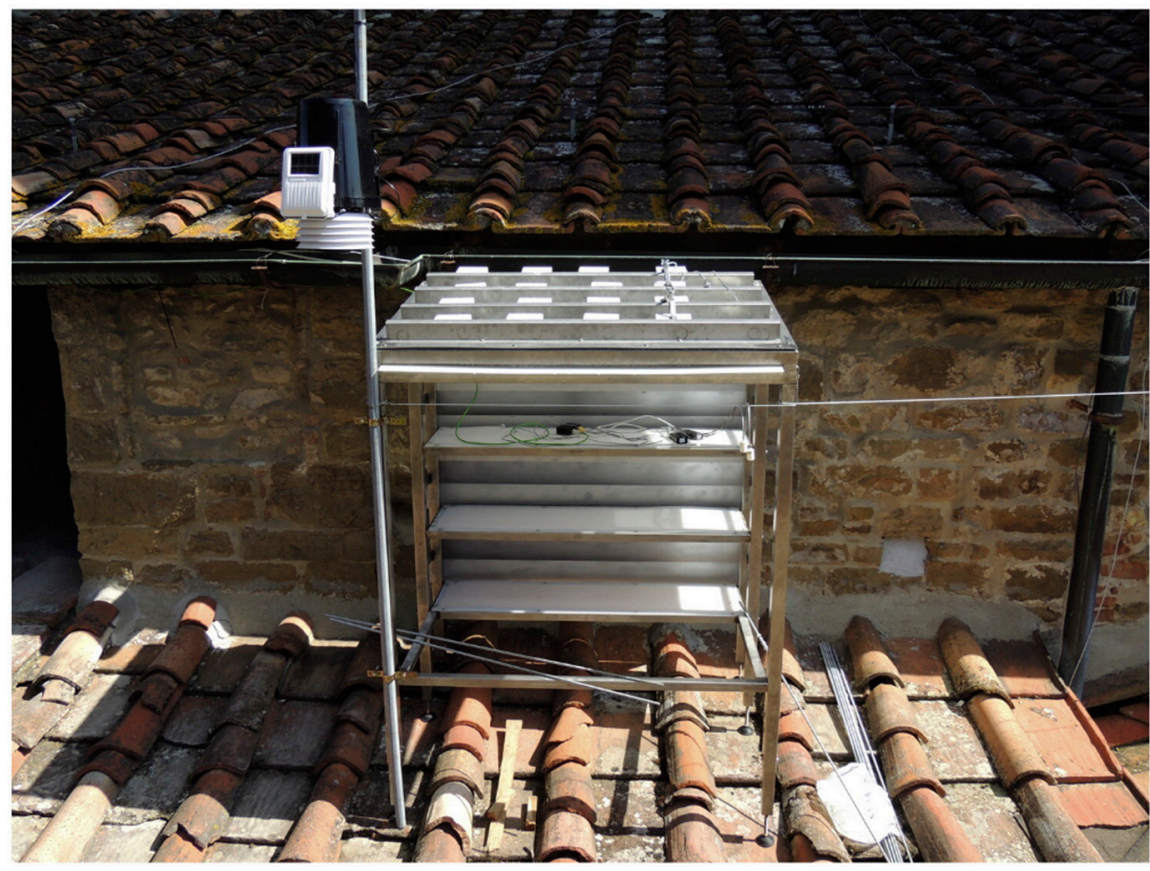

Figure 7. Carrara marble specimens under field exposure testing [38].

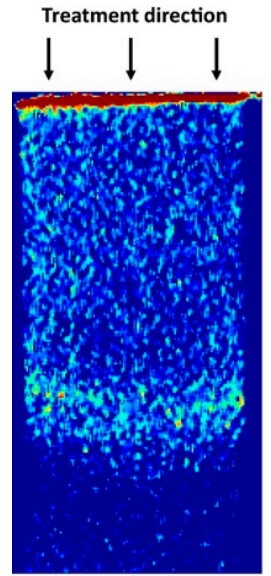

$2 \mathrm{ml} \mathrm{CaLoSil}{ }^{\otimes} \mathrm{E} 25$

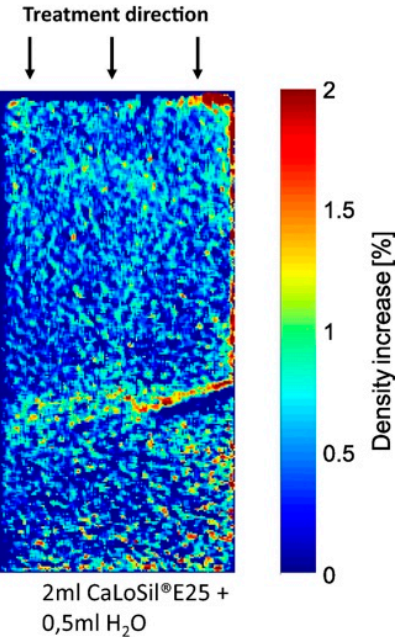

$0,5 \mathrm{ml} \mathrm{H} \mathrm{H}_{2} \mathrm{O}$

Figure 8. X-ray radiographic images of samples treated with CaLoSiLß(left) and CaLoSiLßand immediately water (right) [48].

Lately, a number of published studies have focused on the consolidation of bio-calcarenites [31-33], i.e., calcarenites containing fossils. Calcarenites are typically derived from the erosion of older rocks of limestones or dolostones and by nature are very porous and, therefore, more vulnerable to decay, particularly when close to the seashore. Weathering of calcarenites causes calcite leaching and, in continuously water saturated areas, calcite gets washed away, further increasing porosity and mechanical weakness. For the consolidation of biocalcarenites, two different nanolime dispersions have been proposed in an effort to avoid the back-migration of lime nanoparticles [12]. One suggests the use of diammonium hydrogenphosphate, $\left(\mathrm{NH}_{4}\right)_{2} \mathrm{HPO}_{4}(\mathrm{DAP})$ together with $\mathrm{Ca}(\mathrm{OH})_{2}$. The reaction of $\mathrm{HPO}_{4}{ }^{-}$with $\mathrm{CaCO}_{3}$ gives hydroxyapatite (HAP) which is highly stable and compatible with the limestone substrate. However, the metastable phases include calcium phosphate, such as dicalcium 
phosphate dehydrate or octacalcium phosphate, and in certain cases these products outnumber the HAP produced. Secondly, fractions of unreacted phosphate remain in the stone and necessitate additional calcium sources for further reactions. Thirdly, alterations of lightness are non-negligible [33]. Nevertheless, Weththimuni et al. [31] developed a nanolime and DAP consolidant which was applied on a very porous Italian bio-calcarenite, the Lecce stone, which has been extensively used for most of the Baroque structures in the Salento region. The stone has an open porosity of $38.9 \%$. It is composed mainly of calcite $(93 \%-97 \%)$ with other minor components such as muscovite, feldspars, and quartz. The nanolime consolidant (nanolime in $5 \mathrm{~g} / \mathrm{L}$ dispersed in isopropanol) was first applied using a brush until surface saturation was reached. Twenty-four hours later, the DAP solution was applied on the same surface, and the treated stone samples were allowed to dry for two weeks at room temperature. Another set of specimens was only treated with DAP for comparison purposes. Artificially weathered and treated stones were tested with water capillary absorption tests, permeability tests, color measurements, XRD analysis, SEM imaging, SEM-EDX analysis, and MIP. The consolidation efficiency was investigated by the Scotch Tape test and by determining the resistance to salt crystallization. The SEM-EDX mapping showed a homogeneous distribution of present calcium phosphates; however, the chromatic changes were within acceptable limits. The results suggest that the hydroxyapatite formed by the nanolime plus DAP application enhanced the hydric properties, surface cohesion, and strength of the treated stone to the extent that it can be suggested for in situ applications. It would have been of great interest to have had the comparison of the isopropanol nanolime dispersion after two applications with the nanolime plus DAP application.

To avoid the formation of calcium phosphates, a new method for the production of nanolimes has been introduced for superficial consolidation of Agrigento (Italy) bio-calcarenite stones [32]. This new, patented method is based on the process of ion exchange and allows for the production of pure and crystalline nanolime particles within a few minutes. The three synthetized dispersions were applied by brushing on irregularly shaped stones which were then tested for water absorption by capillarity, STT, DRM, MIP, and spectrophotometry. Results showed that the nanoparticles produced were highly reactive, completing the carbonation reaction within 30 minutes of the application. The best results were obtained for the alcoholic suspension with a solid concentration of $10 \mathrm{~g} / \mathrm{L}$ after three treatments, with a $60 \%$ reduction in surface material removal and a $50 \%$ reduction in water adsorption by capillary. A white layer was also observed on the surface which is suggested to be further investigated in a future study.

In a subsequent study, this team extended the initial preliminary results [32] to a complete investigation [33] according to procedures described in the standards. In this study, nanolime particles were also fully dispersed in water in an effort to limit hazards from the volatile organic compounds present in alcoholic nanolime dispersions. Comparison with varied dispersion medium, alcohol (ethanol $100 \%$ ), water (100\%), and a mixture of both (ethanol $50 \%$ and water $50 \%$ ) applied by spraying or brushing was made. Efficiency was assessed via water absorption by capillarity, STT, DRM, MIP, and stereomicroscopy. The spraying technique and the aqueous dispersion was found to provide the best results with a $90 \%$ reduction of materials removal from the surface for $1 \mathrm{~cm}$ depth. Although this non-commercial product is yet to be applied to form mass consolidation, one cannot disregard that aqueous dispersions are greener and the issue of the back migration of particles toward the surface or that of the formation of calcium carbonate polymorphs is eradicated.

In the latest published study by Otero et al. [49], a relationship between the pore size of the substrate and the nanolime particle size was established. Nanorestore Plus Propanol 5囚and synthetized with the anionic exchange procedure nanolime at $5 \mathrm{~g} / \mathrm{l}$ dispersed in $50 \%$ water and $50 \%$ isopropanol were selected as consolidants of two types of weathered limestones: a Doulting stone capital from Wells Cathedral and another limestone of unknown origin. The elemental composition of the limestone was determined via $\mathrm{XRF}$ analysis, the mineralogical composition via $\mathrm{XRD}$, and the porosity of the stones via MIP. The dispersions were applied by brush in outdoor conditions on a daily basis until $500 \mathrm{mg}$ of calcium hydroxide was absorbed. The total duration lasted for 30 days and then samples were stored 
outdoors in sheltered conditions at RH $60 \%-80 \%$, monitored by a humidistat. Untreated samples were also stored for comparison. The effectiveness of the treatment was tested with the phenolphthalein solution, the open porosity, and the pore size distribution via MIP, the water absorption by capillarity, the surface cohesion via STT and DRM, and color changes with spectrophotometry. A consolidation depth of 14 to $20 \mathrm{~mm}$ was reached. Both treatments reduced the porosity and water absorption by capillarity, while increasing the surface cohesion and strength, although it also caused limited whitening of the treated surfaces. Most importantly, nanolime consolidants with larger particle size nanolimes were found to be the most appropriate for substrates with larger pores, whereas nanolime consolidants with a smaller particle size close both smaller and larger pores equally.

Table 2. Tabulated review of materials, experimental techniques, and main findings.

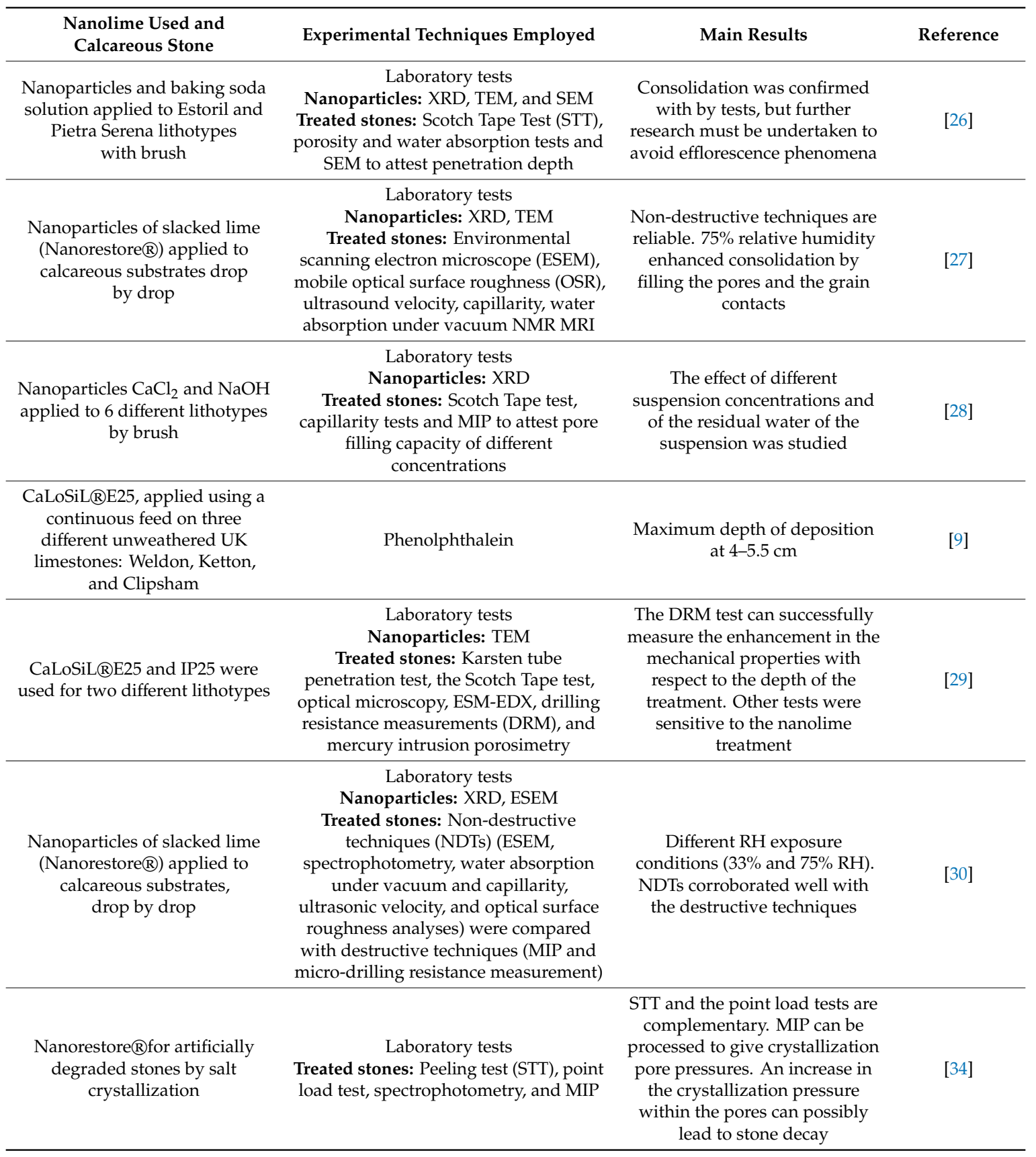


Table 2. Cont

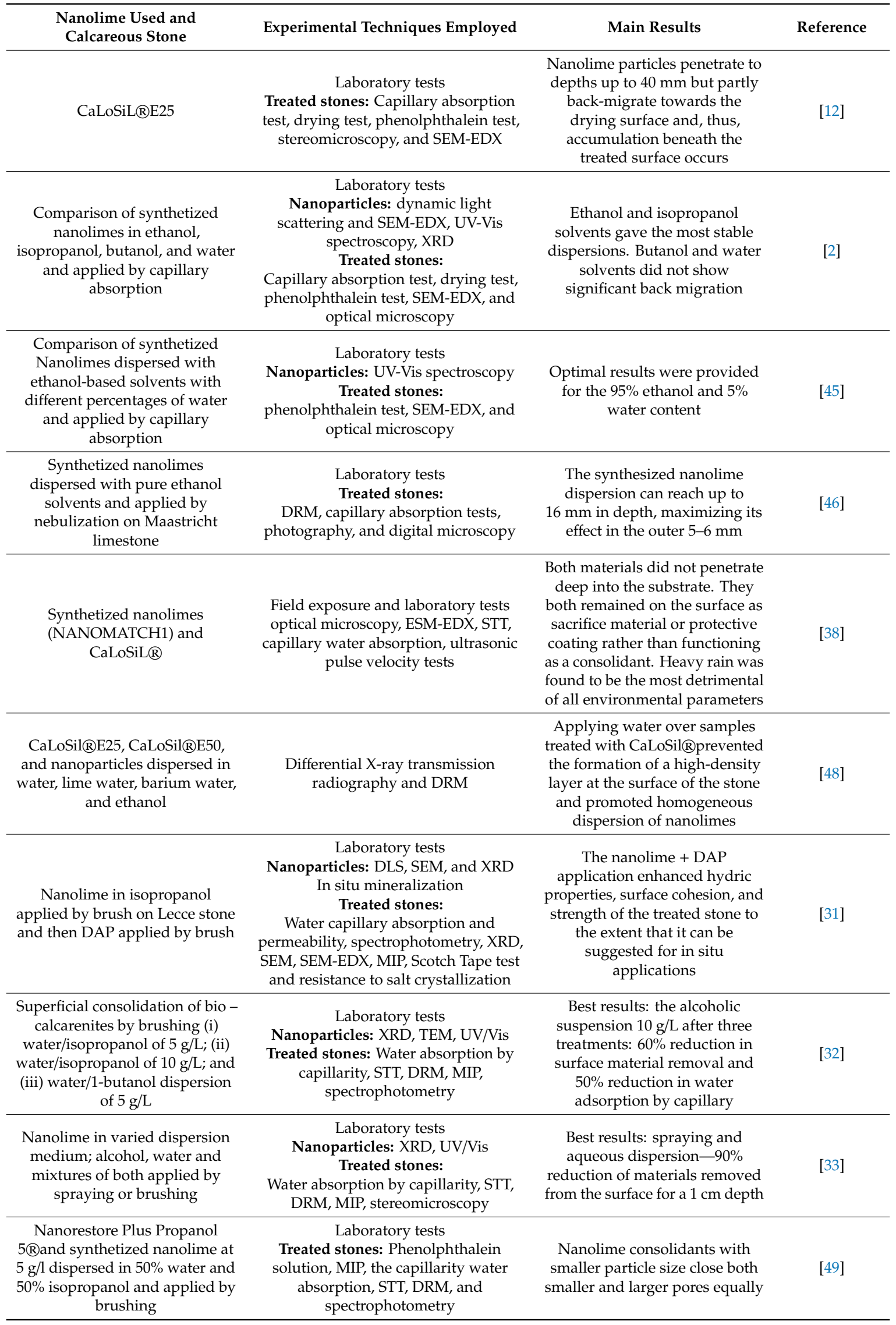




\subsection{Other Aspects}

There are some additional aspects that should be considered, mostly relating to the metastable phases that are formed during the carbonation of $\mathrm{Ca}(\mathrm{OH})_{2}$ and are discussed in this section.

It is acknowledged that the mechanism of carbonation of nanolime is critical for the consolidation's effectiveness, and that relative humidity affects the percentage of $\mathrm{Ca}(\mathrm{OH})_{2}$ transformation into $\mathrm{CaCO}_{3}$ as well as the different $\mathrm{CaCO}_{3}$ phases formed. The metastable $\mathrm{CaCO}_{3}$ phases include amorphous calcium carbonate (ACC), monohydrocalcite, vaterite (known to limit consolidation), and aragonite before or during the formation of the stable calcite [11]. In this recent study by Rodriguez-Navarro et al. [10], the kinetics and the mechanism of carbonation were investigated using the commercial product CaLoSil@E-25. The $\mathrm{CaCO}_{3}$ polymorphs were studied via XRD, thermal gravimetric analyses (TGA), transmission and field emission electron microscopy imaging, and in situ Raman spectroscopy. The authors, amongst other findings, concluded that the carbonation process follows the Ostwald's step rule according to the following sequence: ACC $\rightarrow$ vaterite $\rightarrow$ aragonite $\rightarrow$ calcite. The presence of ethanol adsorbed on nanolime particles is responsible for the formation of metastable aragonite and vaterite, whereas its absence signals the sole formation of calcite. Lastly, the study of the multistep and non-classical crystal growth processes must be applied for the design of novel nanolime consolidants.

Adding to this research, it has been established that $\mathrm{Ca}(\mathrm{OH})_{2}$ nanoparticles, when dispersed in alcohol, transform into calcium alkoxides. More specifically, reaction with ethanol produced Ca-ethoxide and reaction with isopropanol produced Ca-isopropoxide which both reduced the rate of the carbonation reaction inducing the formation of metastable vaterite [50]. To confirm these findings TEM, XRD crystallographic analyses, thermal gravimetric analysis, and differential scanning calorimetry coupled with Fourier transform infrared spectroscopy (FTIR) were performed, and a commercial nanolime, CaLoSil $\AA$, was partially transformed into Ca-ethoxide following storage for up to 2 weeks in an oven at $60^{\circ} \mathrm{C}$. When the control sample was exposed at $80 \% \mathrm{RH}$ at $20{ }^{\circ} \mathrm{C}$, it fully carbonated within two days, whereas the Ca-alkoxides took two weeks to fully carbonate. The lesson learned is that, eventually, even Ca-alkoxides will hydrolyze and convert into $\mathrm{Ca}(\mathrm{OH})_{2}$ which will undergo full carbonation at a slower rate, but care should be exercised with storage conditions in order to prevent the partial conversion of nanolime alcohol dispersions into Ca-alkoxides.

\subsection{Some Remarks on Additional Characterization Methods that can be Employed in Future Investigations}

As analyzed in the sections above, only one team, Rodriguez-Navarro et al. [11], have employed one of the most useful techniques for the characterization of nanoparticles and nano-modified formulations. This technique is the thermal gravimetric/differential thermal gravimetric analysis (TGA/dTG) and by this method, the mass change of a sample is monitored as a function of temperature change. A typical analysis comprises heating up a sample from room temperature to $1000^{\circ} \mathrm{C}$ at a rate of $10^{\circ} \mathrm{C} / \mathrm{min}$. Different phases are distinguished according to the hydrates that decompose as the temperature increases. It has been found to yield very precise information on the phases developed particularly when coupled with XRD [8,21,22,51].

Moreover, although atomic force microscopy (AFM) has been proven ideal for the studying or the interaction properties of surfaces of nanoparticles dispersions [19], this method has not been utilized at all in any of the research presented. It should also be noted that AFM using automated analysis software is preferred to DLS for characterizing size distributions as it provides an accurate and fast results [52].

Fourier transform infrared (FTIR) spectroscopy can be utilized to map crystalline and amorphous phases present in the hardened formulations. Fourier transform infrared is a powerful technique for identifying silicon- and calcium-derived networks and can therefore provide significant information that relates to the durability of the proposed formulations [53]. 
Lastly, with respect to the formulations studied, mercury intrusion porosimetry (MIP) tests were carried out to collect information on porosity and of the pore refinement that may be taking place in the nano-modified formulations [54]. The MIP tests allow for the measurement of both bulk and apparent density. In bulk density, the open (interconnected) and closed porosity are included, while, in apparent density, the open porosity is excluded. Subsequently, the apparent porosity provides an estimate of the open pores [55]. The total amount of pores, the median pore area diameter, and the average pore diameter may also be estimated, although studies have suggested that MIP pore size distribution estimates are actually unreliable [56]. Moreover, the samples need to be dried prior to the execution of the measurement, and drying procedures generally influence the results, and only relatively small samples can be analyzed, and, therefore, it may not necessarily be representative of the bulk. For this reason, some non-destructive techniques are thoroughly discussed in the present review.

\subsection{A Framework of Assessment Tools/Characterization Methods}

From all work reviewed in the previous sections, it is evident that the efficacy of consolidants is a multidimensional issue, affected by a number of parameters relating to the nanolime properties themselves (concentration, solvent type, etc.), but also to ambiental factors ( $\mathrm{RH}$, temperature, etc.) and other factors such as storage conditions and application methods as shown in Table 3.

Table 3. Factors influencing the effectiveness of nanolime consolidants.

\begin{tabular}{ccc}
\hline Nanolime Properties & Ambiental Factors & Other Parameters \\
\hline Concentration & $\mathrm{RH}$ & Nature and porosity of substrate \\
\hline Particle size & Temperature & $\begin{array}{c}\text { Amount of consolidant deposited } \\
\text { (surface or mass consolidation) }\end{array}$ \\
\hline $\begin{array}{c}\text { Solvent type } \\
\text { of particles }\end{array}$ & Exposure time & Storage conditions-duration \\
\hline Kinetic stability and reactivity & Available $\mathrm{CO}_{2}$ & $\begin{array}{c}\text { Application method and number } \\
\text { of applications }\end{array}$ \\
\hline
\end{tabular}

Given the analysis presented in the preceding sections and all recent advancements in the field of coatings for stones [57], where non-destructive techniques are predominant for assessing the efficacy of the products (water repellence porosity etc.), it can be safely concluded that coupling of destructive and non-destructive techniques (NDTs) will soon be followed by a shift towards pure NDTs, as they are found to be reliable and fast. The additional advantage of testing the same samples over a lengthy period of time therefore allowing to monitor the changes induced with time is of paramount importance for the preservation of national heritage. The consolidation efficiency parameters and the corresponding characterization techniques available are presented in Table 4.

It can be observed that, so far, strength has not been correlated with NDTs. For this, the authors suggest that future research could encompass comparison of ultrasonic pulse velocity tests with STT or DRM. In addition, the an OR Schmidt hammer could give potential correlation. 
Table 4. Efficiency parameters/material properties to be assessed and options available for characterization.

\begin{tabular}{|c|c|}
\hline $\begin{array}{c}\text { Consolidation Efficiency } \\
\text { Parameters/Material Properties }\end{array}$ & Options on Characterization Techniques \\
\hline $\begin{array}{l}\text { Distribution of consolidants } \\
\text { mapping }\end{array}$ & $\begin{array}{l}\text { Differential X-ray radiography imaging (with micro CT-3D representation of } \\
\text { pore structure) } \\
\text { Environmental scanning electron microscopy } \\
\text { Marking agents (phenolphthalein method) } \\
\text { Neutron imaging } \\
\text { Nuclear magnetic resonance (NMR) magnetic resonance imaging (MRI) (to } \\
\text { measure the distribution of nanoproducts inside the pores) }\end{array}$ \\
\hline Consolidation depth & $\begin{array}{l}\text { Differential X-ray radiography imaging } \\
\text { Marking agents (phenolphthalein) } \\
\text { Drilling resistance measurements } \\
\text { X-Ray radiography micro CT } \\
\text { Nuclear magnetic resonance } \\
\text { Small angle neutron imaging }\end{array}$ \\
\hline $\begin{array}{l}\text { Color changes (aesthetic } \\
\text { compatibility) }\end{array}$ & $\begin{array}{l}\text { Spectrophotometry } \\
\text { Stereomicroscopy (or digital microscopy) }\end{array}$ \\
\hline Pore structure & $\begin{array}{l}\text { Mercury intrusion porosimetry (pore size distribution and open porosity) } \\
\text { X-ray radiography micro CT } \\
\text { Small angle neutron imaging } \\
\text { Ultrasonic pulse velocity tests (EN 14579:2004 to assess durability affected by } \\
\text { porosity, the extent of penetration) }\end{array}$ \\
\hline $\begin{array}{l}\text { Surface consolidation, cohesion, } \\
\text { roughness }\end{array}$ & $\begin{array}{l}\text { Scotch Tape test ASTM D3359 } \\
\text { Stereomicroscopy (for surface texture and structure variations) } \\
\text { Drilling resistance measurements } \\
\text { Scanning electron microscopy } \\
\text { Optical surface roughness (for 3D topography maps) }\end{array}$ \\
\hline Strength & $\begin{array}{l}\text { Resistance to salt crystallization } \\
\text { Scotch Tape test } \\
\text { Drilling resistance measurements } \\
\text { Point load test } \\
\text { Thermal gravimetric analysis }\end{array}$ \\
\hline Crystals present, phases formed & $\begin{array}{l}\text { X-ray diffraction } \\
\text { Thermal gravimetric analysis }\end{array}$ \\
\hline Hydric properties & $\begin{array}{l}\text { Capillary absorption test for absorbed water (water absorption coefficient is } \\
\text { determined by EN15801: 2010) } \\
\text { Water absorption under vacuum (UNE-EN 1936:1999) } \\
\text { Water vapor permeability } \\
\text { Karsten tube penetration test (to determine water absorption) } \\
\text { Neutron imaging (to monitor water movement) } \\
\text { Nuclear magnetic resonance (NMR) magnetic resonance imaging (MRI) (to } \\
\text { measure the distribution of water inside the pores) }\end{array}$ \\
\hline $\begin{array}{l}\text { Durability in terms of salt } \\
\text { crystallization }\end{array}$ & Spanish standard UNE-EN: 12370 \\
\hline
\end{tabular}

\section{Conclusions}

In the present review, a number of issues relating to nanolimes suitable for calcareous stone consolidation for historic buildings were clarified:

- The term "effectiveness" was re-defined through a number of efficiency parameters/material properties that should be characterized;

- A significant number of characterization techniques were reviewed for both the characterization of nanoparticles and the effectiveness of the weathering and consolidation treatment (before and after weathering);

- Different applications of nanolimes have been described (brushing, drop-by-drop, immersion, contact capillary, spraying);

- Non-destructive techniques have been highlighted. 
Although current research on the use of nanolime dispersions for superficial consolidation is extensive, research on mass consolidation for penetration depths well beyond $5.5 \mathrm{~cm}$ is still to be presented in the near future. The presented suite of efficiency parameters-characterization techniques can be utilized for the validation of future experimental work in the field.

Author Contributions: Conceptualization, S.P.; methodology, S.P. and E.D.; formal analysis, S.P.; resources, S.P. and E.D.; data curation, S.P. and E.D.; writing—original draft preparation, S.P.; writing—review and editing, S.P. and E.D.

Funding: This research received no external funding.

Conflicts of Interest: The authors declare no conflict of interest.

\section{References}

1. Lubelli, B.; van Hees, R.P.J.; Nijland, T.G.; Bolhuis, J. A new method for making artificially weathered stone specimens for testing of conservation treatments. J. Cult. Herit. 2015, 16, 698-704. [CrossRef]

2. Borsoi, G.; Lubelli, B.; Van Hees, R.; Veiga, R.; Silva, A.S.; Colla, L.; Fedele, L.; Tomasin, P. Effect of solvent on nanolime transport within limestone: How to improve in-depth deposition. Coll. Surf. A Physicochem. Eng. Asp. 2016, 497, 171-181. [CrossRef]

3. Papatzani, S. Effect of nanosilica and montmorillonite nanoclay particles on cement hydration and microstructure. Mater. Sci. Technol. 2016, 32, 138-153. [CrossRef]

4. Tomasin, P.; Mondin, G.; Zuena, M.; el Habra, N.; Nodari, L.; Moretto, L.M. Calcium alkoxides for stone consolidation: Investigating the carbonation process. Powder Technol. 2019, 344, 260-269. [CrossRef]

5. Kapridaki, C.; Verganelaki, A.; Dimitriadou, P.; Maravelaki-Kalaitzaki, P. Conservation of Monuments by a Three-Layered Compatible Treatment of TEOS-Nano-Calcium Oxalate Consolidant and TEOS-PDMS-TiO 2 Hydrophobic/Photoactive Hybrid Nanomaterials. Materials 2018, 11, 684. [CrossRef]

6. Sierra-Fernandez, A.; Gomez-Villalba, L.S.; Rabanal, M.E.; Fort, R. New nanomaterials for applications in conservation and restoration of stony materials: A review. Mater. Constr. 2017, 67, 107. [CrossRef]

7. Da Fonseca, B.S.; Ferreira, M.J.; Taryba, M.G.; Piçarra, S.; Pinto, A.P.F.; de Fátima Montemor, M. Alkoxysilane-based sols for consolidation of carbonate stones: Impact of the carbonate medium in the sol-gel processes. J. Cult. Herit. 2019, 37, 63-72. [CrossRef]

8. Papatzani, S.; Badogiannis, E.G.; Paine, K. The pozzolanic properties of inorganic and organomodified nano-montmorillonite dispersions. Constr. Build. Mater. 2018, 167, 299-316. [CrossRef]

9. D'Armada, P.; Hirst, E. Nano-Lime for Consolidation of Plaster and Stone. J. Archit. Conserv. 2012, 18, 63-80. [CrossRef]

10. Rodriguez-Navarro, C.; Suzuki, A.; Ruiz-Agudo, E. Alcohol Dispersions of Calcium Hydroxide Nanoparticles for Stone Conservation. Langmuir 2013, 29, 11457-11470. [CrossRef] [PubMed]

11. Rodriguez-Navarro, C.; Elert, K.; Ševčík, R. Amorphous and crystalline calcium carbonate phases during carbonation of nanolimes: Implications in heritage conservation. CrystEngComm 2016, 18, 6594-6607. [CrossRef]

12. Borsoi, G.; Lubelli, B.; van Hees, R.; Veiga, R.; Silva, A.S. Understanding the transport of nanolime consolidants within Maastricht limestone. J. Cult. Herit. 2016, 18, 242-249. [CrossRef]

13. Daehne, A.; Herm, C. Calcium hydroxide nanosols for the consolidation of porous building materials-Results from EU-STONECORE. Herit. Sci. 2013, 1, 11. [CrossRef]

14. Ylmén, R.; Jäglid, U.; Steenari, B.-M.; Panas, I. Early hydration and setting of Portland cement monitored by IR, SEM and Vicat techniques. Cem. Concr. Res. 2009, 39, 433-439. [CrossRef]

15. Papatzani, S.; Grammatikos, S.; Adl-Zarrabi, B.; Paine, K. Pore-structure and microstructural investigation of organomodified/Inorganic nano-montmorillonite cementitious nanocomposites. Am. Inst. Phys. 2018, 1957, 030004. [CrossRef]

16. Scrivener, K.L.; Füllmann, T.; Gallucci, E.; Walenta, G.; Bermejo, E. Quantitative study of Portland cement hydration by X-ray diffraction/Rietveld analysis and independent methods. Cem. Concr. Res. 2004, 34, 1541-1547. [CrossRef]

17. Soin, A.V.; Catalan, L.J.J.; Kinrade, S.D. A combined QXRD/TG method to quantify the phase composition of hydrated Portland cements. Cem. Concr. Res. 2013, 48, 17-24. [CrossRef] 
18. Papatzani, S.; Paine, K. Inorganic and organomodified nano-montmorillonite dispersions for use as supplementary cementitious materials-A novel theory based on nanostructural studies. Nanocomposites 2017, 3, 2-19. [CrossRef]

19. Calabria-Holley, J.; Papatzani, S.; Naden, B.; Mitchels, J.; Paine, K. Tailored montmorillonite nanoparticles and their behaviour in the alkaline cement environment. Appl. Clay Sci. 2017, 143, 67-75. [CrossRef]

20. Papatzani, S.; Paine, K. From Nanostructural Characterization of Nanoparticles to Performance Assessment of Low Clinker Fiber-Cement Nanohybrids. Appl. Sci. 2019, 9, 22. [CrossRef]

21. Papatzani, S.; Paine, K. Polycarboxylate/nanosilica-modified quaternary cement formulations - enhancements and limitations. Adv. Cem. Res. 2018, 30, 256-269. [CrossRef]

22. Papatzani, S.; Paine, K. Lowering cement clinker: A thorough, performance based study on the use of nanoparticles of $\mathrm{SiO}_{2}$ or montmorillonite in Portland limestone nanocomposites. Eur. Phys. J. Plus 2018, 133, 430. [CrossRef]

23. Bohren, C.F.; Huffman, D.R. Absorption and Scattering of Light by Small Particles; John Wiley \& Sons: Hoboken, NJ, USA, 1998. [CrossRef]

24. Pecora, R. Dynamic Light Scattering Measurement of Nanometer Particles in Liquids. J. Nanoparticle Res. 2000, 2, 123-131. [CrossRef]

25. Tomaszewska, E.; Soliwoda, K.; Kadziola, K.; Tkacz-Szczesna, B.; Celichowski, G.; Cichomski, M.; Szmaja, W.; Grobelny, J. Detection Limits of DLS and UV-Vis Spectroscopy in Characterization of Polydisperse Nanoparticles Colloids. J. Nanomater. 2013, 2013, 60. [CrossRef]

26. Daniele, V.; Taglieri, G.; Quaresima, R. The nanolimes in Cultural Heritage conservation: Characterisation and analysis of the carbonatation process. J. Cult. Herit. 2008, 9, 294-301. [CrossRef]

27. López-Arce, P.; Gomez-Villalba, L.S.; Pinho, L.; Fernández-Valle, M.E.; de Buergo, M.Á.; Fort, R. Influence of porosity and relative humidity on consolidation of dolostone with calcium hydroxide nanoparticles: Effectiveness assessment with non-destructive techniques. Mater. Charact. 2010, 61, 168-184. [CrossRef]

28. Daniele, V.; Taglieri, G. Nanolime suspensions applied on natural lithotypes: The influence of concentration and residual water content on carbonatation process and on treatment effectiveness. J. Cult. Herit. 2010, 11, 102-106. [CrossRef]

29. Pesce, G.L.; Morgan, D.; Odgers, D.; Henry, A.; Allen, M.; Ball, R.J. Consolidation of weathered limestone using nanolime. Proc. Inst. Civ. Eng. Constr. Mater. 2013, 166, 213-228. [CrossRef]

30. López-Arce, P.; Zornoza-Indart, A.; Gomez-Villalba, L.S.; Fort, R. Short- and Longer-Term Consolidation Effects of Portlandite (CaOH)2 Nanoparticles in Carbonate Stones. J. Mater. Civ. Eng. 2013, 25, 1655-1665. [CrossRef]

31. Weththimuni, M.L.; Licchelli, M.; Malagodi, M.; Rovella, N.; la Russa, M. Consolidation of bio-calcarenite stone by treatment based on diammonium hydrogenphosphate and calcium hydroxide nanoparticles. Measurement 2018, 127, 396-405. [CrossRef]

32. Taglieri, G.; Otero, J.; Daniele, V.; Gioia, G.; Macera, L.; Starinieri, V.; Charola, A.E. The biocalcarenite stone of Agrigento (Italy): Preliminary investigations of compatible nanolime treatments. J. Cult. Herit. 2018, 30, 92-99. [CrossRef]

33. Daniele, V.; Taglieri, G.; Macera, L.; Rosatelli, G.; Otero, J.; Charola, A.E. Green approach for an eco-compatible consolidation of the Agrigento biocalcarenites surface. Constr. Build. Mater. 2018, 186, 1188-1199. [CrossRef]

34. Ruffolo, S.A.; La Russa, M.F.; Aloise, P.; Belfiore, C.M.; Macchia, A.; Pezzino, A.; Crisci, G.M. Efficacy of nanolime in restoration procedures of salt weathered limestone rock. Appl. Phys. A 2014, 114, 753-758. [CrossRef]

35. British Standards Institution. BS EN 12370:1999 Natural Stone Test Methods: Determination of Resistance to Salt Crystallization; BSI: London, UK, 1999.

36. British Standards Institution. BS EN 13755:2008 Natural Stone Test Methods: Determination of Water Absorption at Atmospheric Pressure; BSI: London, UK, 2008.

37. Bonazza, A.; Vidorni, G.; Natali, I.; Ciantelli, C.; Giosuè, C.; Tittarelli, F. Durability assessment to environmental impact of nano-structured consolidants on Carrara marble by field exposure tests. Sci. Total Environ. 2017, 575, 23-32. [CrossRef]

38. ASTM D5313. Standard Test Method for Evaluation of Durability of Rock for Erosion Control Under Wetting and Drying Conditions; ASTM International: West Conshohocken, PA, USA, 2013. 
39. UNE-EN 1936:2007. Conservation of Cultural Property-Test Methods-Determination of Water Absorption by Capillarity; AENOR: Madrid, Spain, 2010.

40. Giorgi, R.; Dei, L.; Baglioni, P. A New Method for Consolidating Wall Paintings Based on Dispersions of Lime in Alcohol. Stud. Conserv. 2000, 45, 154-161. [CrossRef]

41. UNE-EN. 1936:2007 Métodos de Ensayo Para Piedra Natural. Determinación de la Densidad Real y Aparente y de la Porosidad Abierta y Total; AENOR: Madrid, Spain, 2007.

42. Papatzani, S.; Paine, K.; Calabria-Holley, J. A comprehensive review of the models on the nanostructure of calcium silicate hydrates. Constr. Build. Mater. 2015, 74, 219-234. [CrossRef]

43. ASTM D3359/2017 Standard. Test Methods for Rating Adhesion by Tape Test; ASTM International: West Conshohocken, PA, USA, 2017.

44. Borsoi, G.; Lubelli, B.; van Hees, R.; Veiga, R.; Silva, A.S. Optimization of nanolime solvent for the consolidation of coarse porous limestone. Appl. Phys. A 2016, 122, 846. [CrossRef]

45. Borsoi, G.; Lubelli, B.; van Hees, R.; Veiga, R.; Silva, A.S. Evaluation of the effectiveness and compatibility of nanolime consolidants with improved properties. Constr. Build. Mater. 2017, 142, 385-394. [CrossRef]

46. British Standards Institution. BS EN 14579:2004 - Natural Stone Test Methods: Determination of Sound Speed Propagation; BSI: London, UK, 2005.

47. Niedoba, K.; Slížková, Z.; Frankeová, D.; Nunes, C.L.; Jandejsek, I. Modifying the consolidation depth of nanolime on Maastricht limestone. Constr. Build. Mater. 2017, 133, 51-56. [CrossRef]

48. Otero, J.; Starinieri, V.; Charola, A.E. Influence of substrate pore structure and nanolime particle size on the effectiveness of nanolime treatments. Constr. Build. Mater. 2019, 209, 701-708. [CrossRef]

49. Rodriguez-Navarro, C.; Vettori, I.; Ruiz-Agudo, E. Kinetics and Mechanism of Calcium Hydroxide Conversion into Calcium Alkoxides: Implications in Heritage Conservation Using Nanolimes. Langmuir 2016, 32, 5183-5194. [CrossRef]

50. Papatzani, S.; Grammatikos, S.; Paine, K. Permeable Nanomontmorillonite and Fibre Reinforced Cementitious Binders. Materials 2019, 12, 3245. [CrossRef]

51. Hoo, C.M.; Starostin, N.; West, P.; Mecartney, M.L. A comparison of atomic force microscopy (AFM) and dynamic light scattering (DLS) methods to characterize nanoparticle size distributions. J. Nanoparticle Res. 2008, 10, 89-96. [CrossRef]

52. Calabria-Holley, J.; Paine, K.; Papatzani, S. Effects of nanosilica on the calcium silicate hydrates in Portland cement-fly ash systems. Adv. Cem. Res. 2015, 27, 187-200. [CrossRef]

53. Wild, S. A discussion of the paper: Mercury porosimetry: An inappropriate method for the measurement of pore size distributions in cement-based materials. Author's reply. Cem. Concr. Res. 2001, 31, 1653-1656. [CrossRef]

54. Adamaki, V. Manufacturing and Characterisation of Ti-Suboxides for Sensing and Energy Applications. Ph.D. Thesis, University of Bath, Bath, UK, 2015.

55. Diamond, S. Mercury porosimetry: An inappropriate method for the measurement of pore size distributions in cement-based materials. Cem. Concr. Res. 2000, 30, 1517-1525. [CrossRef]

56. Raneri, S.; Barone, G.; Mazzoleni, P.; Alfieri, I.; Bergamonti, L.; De Kock, T.; Cnudde, V.; Lottici, P.P.; Lorenzi, A.; Predieri, G.; et al. Efficiency assessment of hybrid coatings for natural building stones: Advanced and multi-scale laboratory investigation. Constr. Build. Mater. 2018, 180, 412-424. [CrossRef]

57. Raneri, S.; Barone, G.; Mazzoleni, P.; Alfieri, I.; Bergamonti, L.; De Kock, T.; Cnudde, V.; Lottici, P.P.; Lorenzi, A.; Predieri, G.; et al. Multi-scale laboratory routine in the efficacy assessment of conservative products for natural stones. MethodsX 2018, 5, 1095-1101. [CrossRef]

(C) 2019 by the authors. Licensee MDPI, Basel, Switzerland. This article is an open access article distributed under the terms and conditions of the Creative Commons Attribution (CC BY) license (http://creativecommons.org/licenses/by/4.0/). 